\title{
Renovando nuestro compromiso hacia una continuidad irrenunciable
}

La designación del Comité de Edición del presente volumen, permite renovar una vez más el compromiso de asumir la difícil tarea de difundir los trabajos de investigación realizados en nuestra facultad a través de su órgano oficial, ODONTOLOGÍA SANMARQUINA, revista creada para publicar artículos originales desarrollados en las diferentes líneas de investigación comprendidos en todas las especialidades del vasto campo de la Estomatología. Además publica, revisiones bibliográficas, casos clínicos y artículos de interés odontológico; de este modo, la Universidad cumple con uno de sus objetivos fundamentales, la creación del conocimiento y su divulgación a través de publicaciones científicas, contribuyendo activamente con el desarrollo del país.

Los costos de la presente edición no ha contado con el financiamiento total como en los años anteriores, por lo que creemos oportuno manifestar una vez más nuestro sincero agradecimiento al Consejo Superior de Investigaciones (CSI), que ha hecho posible cumplir con este encargo. Lamentablemente esta siluación ha tenido consecuencias cuantitativas obligando reducir, respecto a ediciones anteriores, el tiraje y el número de paginas de ODONTOLOGla SAMMARQUINA; sin embargo, a pesar de hechos adversos nos propusimos por una irrenunciable actitud elemental de principios, seguir adelante a fin de mantener la periodicidad de ODONTOLOGÍA SANMARQUINA, sin escatimar esfuerzos para preservar la calidad y pulcritud que una revista de este género exige, por la institución a la cual representa y por la comunidad intelectual a la qué va dirigida.

Es de esperar que el aspecto financiero de ODONTOLOGÍA SANMARQUINA se revierta en los próximos volúmenes en bien de los objetivos institucionales dando a la investigación y su difusión el sitial que le corresponde, acorde con los principios de una «Universidad Abierta al Futuro».

Debido a la acogida que se nos ha brindado y a las múltiples expresiones de felicitación y aliento que hemos recibido, pensamos que estamos cumpliendo con cimentar las formalidades de una publicación especializada cuyo objetivo es representar genuinamente el quehacer científico de nuestra casa de estudios. Desde luego que esta labor no hubiese sido posible sin el apoyo desinteresado de nuestros investigadores que con sus artículos han aportado conocimientos, experiencias y sugerencias para llevar adelante esta edición; para ellos nuestra eterna gratitud.

Somos concientes a pesar de las limitaciones, que la mayoría de las revistas latinoamericanas, muy en particular la nuestra, hacen el esfuerzo por estar indizadas. Es nuestro mayor anhelo alcanzar el sitial correspondiente de una revista científica de prestigio. 